Федеральное государственное казенное общеобразовательное учреждение

Тюменское президентское кадетское училище

\title{
Исследование модификационной изменчивости палочника аннамского по окраске тела
}

Авторы: кадет Носков Денис, 6 «Б» класс

Руководитель: преподаватель биологии высшей квалификационной категории, кандидат биологических наук Саранчин Евгений Павлович;

Тюмень, 2021г 


\section{Содержание}

Введение 2

1. Анализ литературных источников 4

2. Материалы и методы исследований 5

3. Анализ экспериментальных данных 7

3.1. Развитие и смертность палочников 7

3.2. Анализ пищевой активности палочников 10

3.3. Анализ динамики окраски палочников 10

Заключение 11

Список использованных источников 13

\section{Введение}

В кабинете биологии ТПКУ уже четыре года живет колония палочников. За это время сменилось уже несколько поколений этих насекомых. Иногда их численность достигала более ста экземпляров, но были случаи, когда колония практически полностью исчезала. Восстановление происходило за счет отложенных ранее яиц, которые хорошо сохранялись в песчаном грунте.

С помощью информации, представленной на сайте «palochniki.ru» [1], нам удалось определить, что наши насекомые относятся к виду «Аннамский палочник» (Baculum extradentatum Brun) родом из Индокитая. А.П. Крапивный и др. [2] отмечают, что палочники выделяются в отдельный отряд Привиденьевые (Plasmoptera) и что для них характерен особый вид размножения - партеногенез. Это означает, что самки откладывают неоплодотворенные яйца из которых появляются особи только женского пола (телитокия).

В мае 2018 года пара молодых нимф были отсажены в террариум с живыми растениями (рис.1) В августе этого же года было зафиксировано различие в окраске у палочников из материнской и дочерней колонии. У пересаженных палочников окрас был более зеленым, а у исходной группы - в окрасе преобладали коричневые тона (рис. 1). 


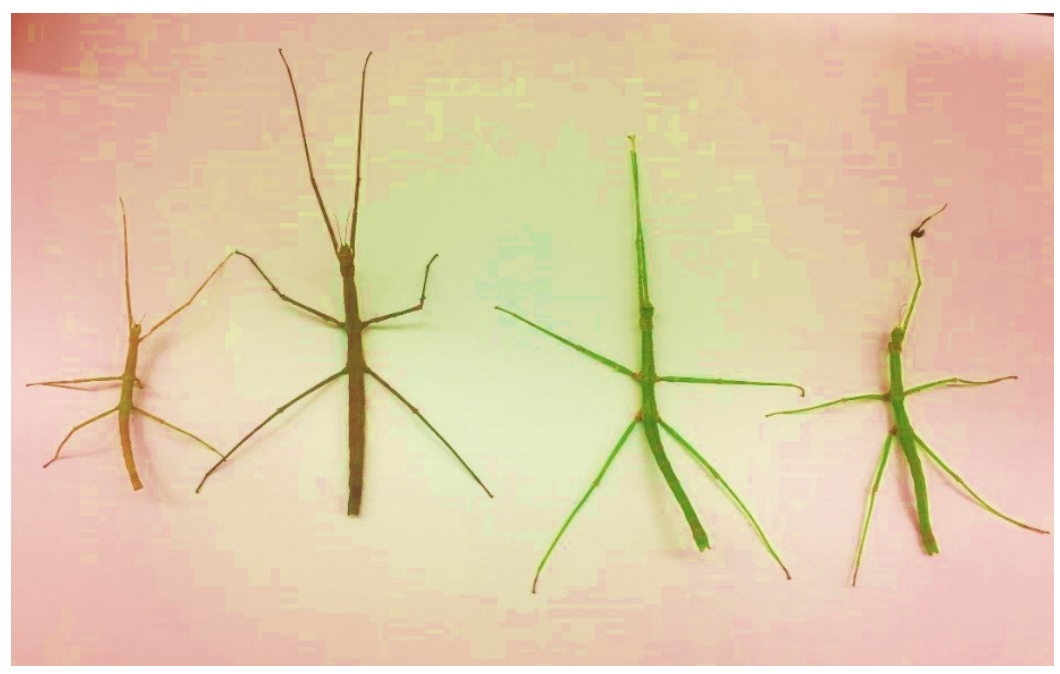

Рис. 1. Фотография палочников из исходной (два слева) и дочерней (два справа) колоний.

Известно, что под влиянием внешних условий развиваются отличия, относящиеся к модификационной или ненаследственной изменчивости. Можно было сделать вывод, что отличия между палочниками из разных колоний носят именно такой - фенотипический характер. Поэтому целью нашей работы мы определили изучение фенотипической изменчивости палочника аннамского под влиянием внешних условий.

Задачи исследования:

1. Изучить научную литературу, посвященную окраске и модификационной изменчивости палочников;

2. Создать группы палочников для проведения эксперимента;

3. Оценить влияние цветового фона на окраску палочников.

Предварительные наблюдения: Отсаженные от основной группы палочники меняли окрас несмотря на генетическую идентичность.

Гипотеза: На скорость развития и окраску палочников оказывает влияние цвет окружающего фона.

Новизна исследований: Анализ исследовательских работ по аннамскому палочнику позволяет утверждать, что изучение представленного направления ранее не проводились.

Актуальность исследований: Палочники представляют собой достаточно экзотичных, но уже распространенных домашних животных. Возможно, 
подобные исследования помогут сделать первые шаги в их селекции и получении первых пород.

\section{1. Анализ литературных источников}

Вероятно, из-за того, что палочники относительно недавно стали использоваться в качестве домашних животных, количество работ по исследованию их биологии незначительно. Чаще всего это исследования связаны с изучением развития и питания палочников в разных экологических условиях [3,4]. Анализ этих источников показывает, что для успешного разведения аннамского палочника требуется высокая пластиковая или стеклянная емкость, системное увлажнение, температура от 22 до $28^{0} \mathrm{C}$ и питание листьями розоцветных, гибискуса, дуба и других растений. По данным этих авторов, развитие от момента выхода нимфы до её половой зрелости составляет 4-5 месяцев. При избыточной плотности колонии (малый объем инсектария) эти насекомые начинают гибнуть от различных увечий или дефицита пищи. Шмелева В. [5] приводит интересные данные о том, что на поедание своего хитинового покрова (экзувия) у филлипинского палочника влияет вид листьев растения скармливаемого животным. Если кормили листьями малины, то шкурки съедались полностью, а если листьями дуба, то небольшая их часть.

Хочется отметить, что среди значительного количества работ, посвященных уходу и разведению аннамского палочника, нам не удалось найти что-либо об изучении окраса этих животных и каком-то влиянии на него внешних факторов. Можно предположить, что из-за образа жизни окраска этих малоподвижных насекомых должна варьировать в зависимости от условий обитания или вида растений. В первую очередь на это может влиять окраска коры деревьев или кустарников. Уместно вспомнить классический пример с березовой пяденицей (Bistons betularia) у которой окраска крыльев варьирует от почти белой до темно коричневой в зависимости от степени загрязненности окружающей среды [6]. 
Промышленный меланизм отмечен у многих видов животных, но для колонии палочников, размножающихся преимущественно партеногенезом, вероятнее всего, будет характерна низкая изменчивость признаков в поколениях, включая окраску тела. Окраска палочников описывается в литературе [7] как криптическая, то есть гармонирующая с фоном и маскирующая по назначению. У насекомых выделяют три уровня закладки окрашивающих пигментов: кутикулярную (самую стойкую); гиподермальную, то есть заложенную в клетках гиподермы; и субгиподермальную, то есть просвечивающую сквозь прозрачные покровы окраску жирового тела, гемолимфы или содержимого кишечника. По нашим наблюдениям, для аннамского палочника характерна гиподермальная пигментация, так как после гибели взрослых особей (имаго) окрас тела меняется с зеленовато-коричневого на однотонно бурый. Именно смена окраски, по мнению исследователей [8], свидетельствует о гиподермальном заложении.

\section{2. Материалы и методы исследований}

Наблюдения и эксперимент проводились на базе кабинета биологии Тюменского ПКУ с 16 октября 2019 по декабрь 2020г. В августе-сентябре 2019 года в колонии палочников, обитающих в тридцатилитровом инсектарии, из отложенных ранее яиц начали появляться нимфы - личинки палочника аннамского. Их появление было сильно растянутым - молодые особи появлялись вплоть до декабря. В октябре был заложен эксперимент по изменению окраски этих насекомых. Из исходной колонии были взяты двенадцать примерно одновозрастных личинок и поровну рассажены в пластиковые контейнеры с разной цветовой гаммой (рис 2). Объем контейнеров составил 1 литр и снаружи они были окрашены в красный (№1), желтый (№2) и зеленый (№3) цвета. На дно слоем в 0,8-1 см насыпали речной песок и поместили выкрашенную акриловой краской в соответствующий цвет веточку от шиповника. Наблюдения фиксировали через 1 день в 
дневнике. Отмечали: температуру окружающей среды $\left({ }^{\circ} \mathrm{C}\right)$, размеры насекомых (мм), их кол-во, окраску, пищевую активность и виды скармливаемых растений. Контролем изначально служили палочники из исходного инсектария. Основным растением для кормления был выбран гибискус (Hibiscus). Также палочникам предлагались листья шиповника (Rosa sp.) и традесканции (Tradescantia).

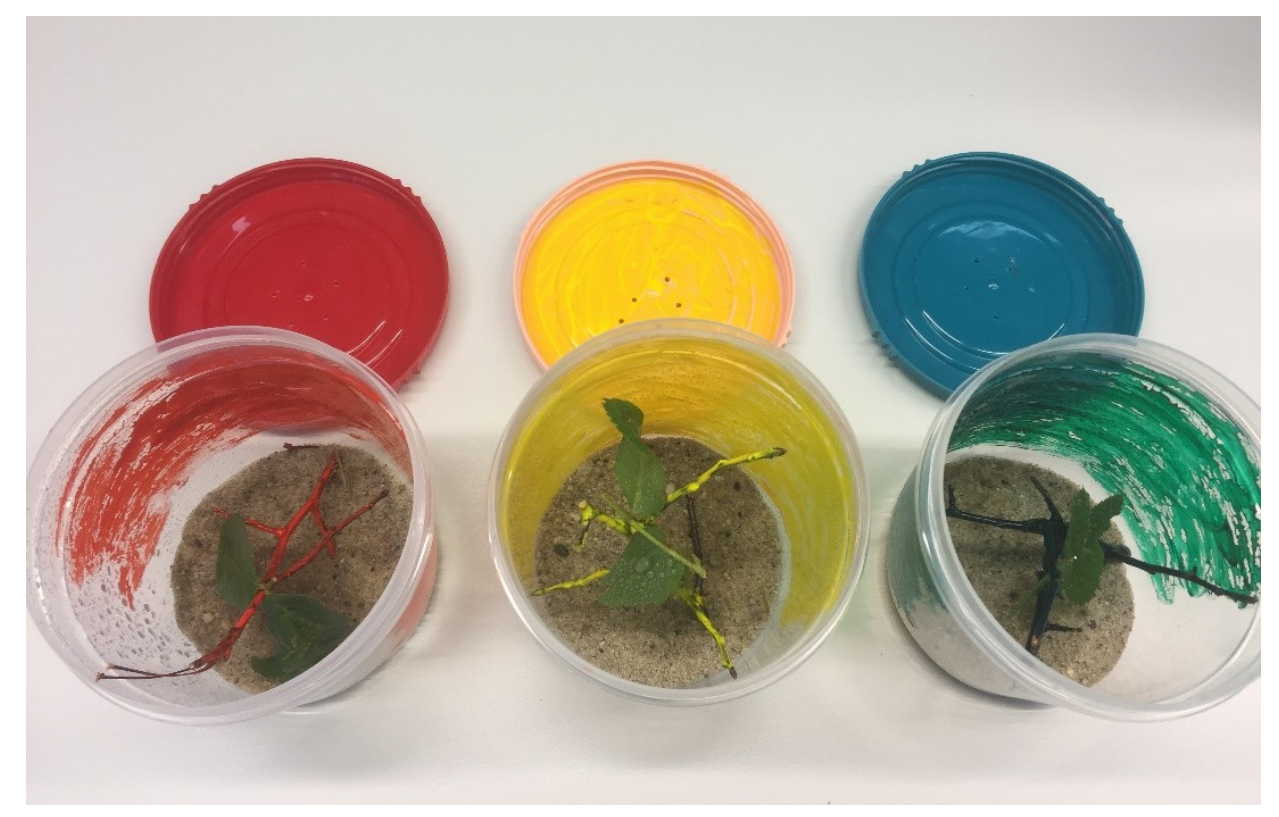

Рис.2. Экспериментальные контейнеры №1-3 (слева - направо)

Позже, в декабре 2019 года для увеличения достоверности наблюдений и дополнительных данных были добавлены еще две группы палочников нимф. Одна группа из четырех особей помещена в аналогичный предыдущим однолитровый пластиковый неокрашенный контейнер № 4. Другие 4 нимфы отсажены в пятилитровый пластиковый контейнер № 5. Во всех контейнерах (рис 3) изначально были просверлены отверстия в равном количестве (6 шт диаметром 3 мм). В пятилитровом контейнере отверстий было сделано два по 0,6 см в диаметре. Основные этапы развития и эксперимента фиксировались при помощи фотоаппарата. В сентябре 2020 года для определения влияния материала контейнеров на жизнедеятельность палочников был заложен еще один опыт. В пластиковые контейнеры и стеклянные банки были посажены 
одновозрастные личинки (приложение 1). В декабре 2020 года этот эксперимент был завершен.

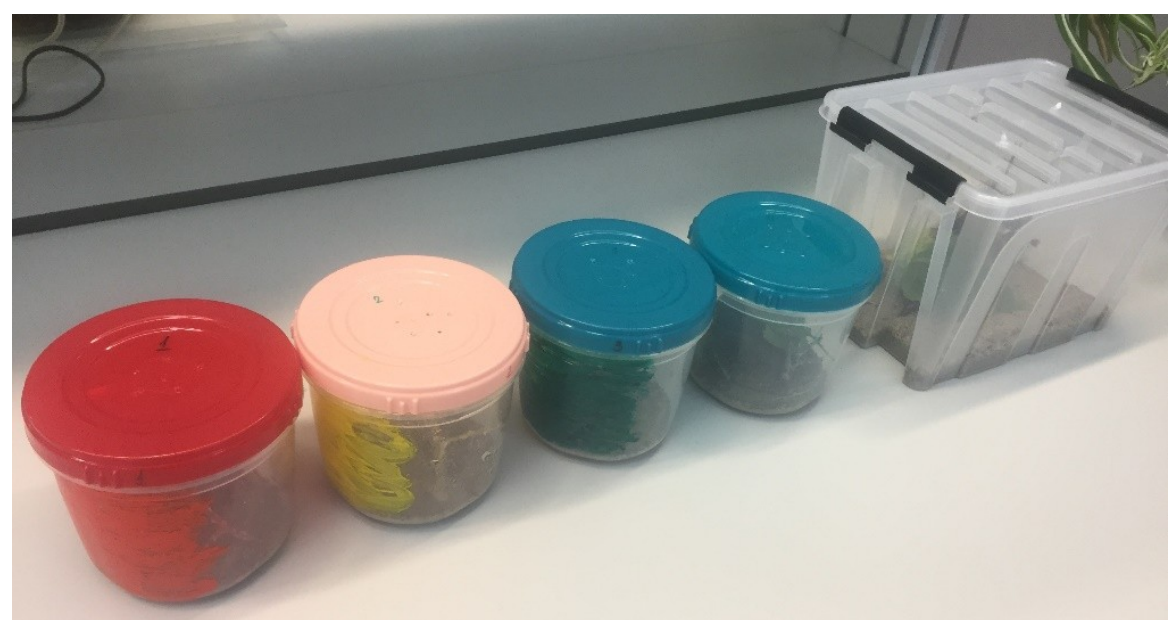

Рис 3. Полный комплект контейнеров для эксперимента.

\section{3. Анализ экспериментальных данных}

Общее время эксперимента составило 133 дня с 16 октября 2019 года до 25 февраля 2020 года. В 2020 году начало изучения пришлось на 22 сентября и завершилось 23 декабря. В разные годы это составило почти четыре - пять месяцев, и по мнению многих исследователей и нашим наблюдениям, этого времени достаточно для полного развития из нимф половозрелых взрослых форм - имаго. Завершение эксперимента в оба года было связано с гибелью последнего образца.

\section{1. Развитие и смертность палочников}

В течение вышеуказанного времени мы проводили наблюдения за количеством и проводили измерения длины тела исследуемых нимф палочника. Картину полученных результатов можно увидеть в таблице 1. Анализ полученных данных показывает, что максимальные сроки выживания нимф палочников составили порядка сто двадцати дней. Это наблюдалось в красном и желтом боксах объемом один литр. В зеленом и бесцветном боксах объемом один литр продолжительность жизни личинок составила 8 декад, а в пятилитровом боксе - порядка 70 дней. Можно предположить, что фон с теплыми красными и желтыми тонами положительно влияет на 
продолжительность жизни аннамского палочника. Следует отметить, что параллельные наблюдения за температурным режимом показали варьирование от 20 до $25 \mathrm{C}^{\circ}$. Это означает, что критических для жизни палочников низких температур не было и влияние на их развитие она не оказывала. За период своей жизни личинки успевали полинять два раза и изменялись в размерах примерно от 13 мм до максимальных 35 мм. В сравнении с материнской колонией наблюдалось сильное отставание во всех боксах (рис 4). Родные «сестры» опережали их на две линьки и соответственно превосходили по размерам в три раза. И это, несмотря на обильное питание. Самое удивительное для нас состояло в том, что даже в относительно просторном пятилитровом контейнере рост личинок шел замедленными темпами.

Таблица 1

Количество и размеры палочников в исследуемых боксах (2019г)

\begin{tabular}{|c|c|c|c|c|c|c|c|c|c|c|}
\hline \multirow{3}{*}{ 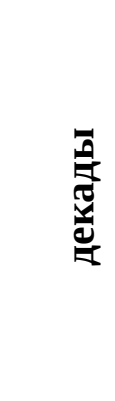 } & \multicolumn{10}{|c|}{ Номер контейнера } \\
\hline & \multicolumn{2}{|c|}{ 1(красный) } & \multicolumn{2}{|c|}{2 (желтый) } & \multicolumn{2}{|c|}{3 (зеленый) } & \multicolumn{2}{|c|}{ 4(бесцв. 1 л) } & \multicolumn{2}{|c|}{ 5(бесцв. 5л) } \\
\hline & 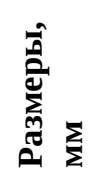 & $\begin{array}{l}\stackrel{8}{5} \\
\stackrel{5}{5}\end{array}$ & 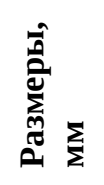 & $\begin{array}{l}0 \\
5 \\
\Xi\end{array}$ & 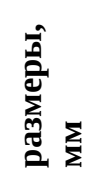 & $\begin{array}{l}\stackrel{8}{5} \\
\stackrel{5}{5}\end{array}$ & 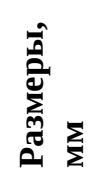 & $\begin{array}{l}0 \\
5 \\
5 \\
\xi\end{array}$ & 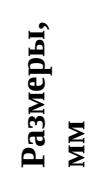 & $\begin{array}{l}0 \\
5 \\
\Xi\end{array}$ \\
\hline $\mathbf{0}$ & $17-20$ & 4 & $16-20$ & 4 & $12-16$ & 4 & - & - & - & - \\
\hline 1 & $17-23$ & 4 & $17-23$ & 4 & $17-20$ & 4 & - & - & - & - \\
\hline 2 & 20-28 & 4 & $17-23$ & 4 & $15-20$ & 4 & - & - & - & - \\
\hline 3 & 20-28 & 4 & $20-20$ & 4 & $20-28$ & 4 & - & - & - & - \\
\hline 4 & $20-28$ & 4 & $20-28$ & 4 & $22-28$ & 4 & - & - & - & - \\
\hline 5 & 20-28 & 4 & $20-28$ & 4 & $22-28$ & 3 & 10-15 & 4 & - & - \\
\hline 6 & $20-28$ & 3 & $20-28$ & 4 & $22-28$ & 2 & $15-15$ & 4 & - & - \\
\hline 7 & $20-28$ & 2 & $20-28$ & 4 & 26 & 1 & $10-15$ & 4 & $10-15$ & 4 \\
\hline 8 & $25-30$ & 2 & 28-30 & 2 & - & $\mathbf{0}$ & $15-20$ & 3 & $15-20$ & 4 \\
\hline 9 & 25-35 & 2 & $30-30$ & 2 & - & $\mathbf{0}$ & $20-25$ & 2 & $20-27$ & 4 \\
\hline
\end{tabular}




\begin{tabular}{|l|l|l|l|l|l|l|l|l|l|l|}
\hline 10 & 33 & 1 & $30-30$ & 2 & - & 0 & $20-25$ & 2 & $20-25$ & 3 \\
\hline 11 & 35 & 1 & $30-30$ & 2 & - & 0 & $30-30$ & 2 & $25-35$ & 3 \\
\hline 12 & 35 & 1 & $33-34$ & 1 & - & 0 & $33-33$ & 2 & $25-35$ & 3 \\
\hline 13 & - & 0 & - & 0 & - & 0 & - & 0 & 35 & 1 \\
\hline
\end{tabular}

Поэтому, мы пришли к промежуточному выводу, что на рост и развитие палочников мог оказывать влияние материал, из которого сделаны контейнеры - пластик. Была вероятность, что он выделяет вещества, отражающиеся на развитии этих животных.

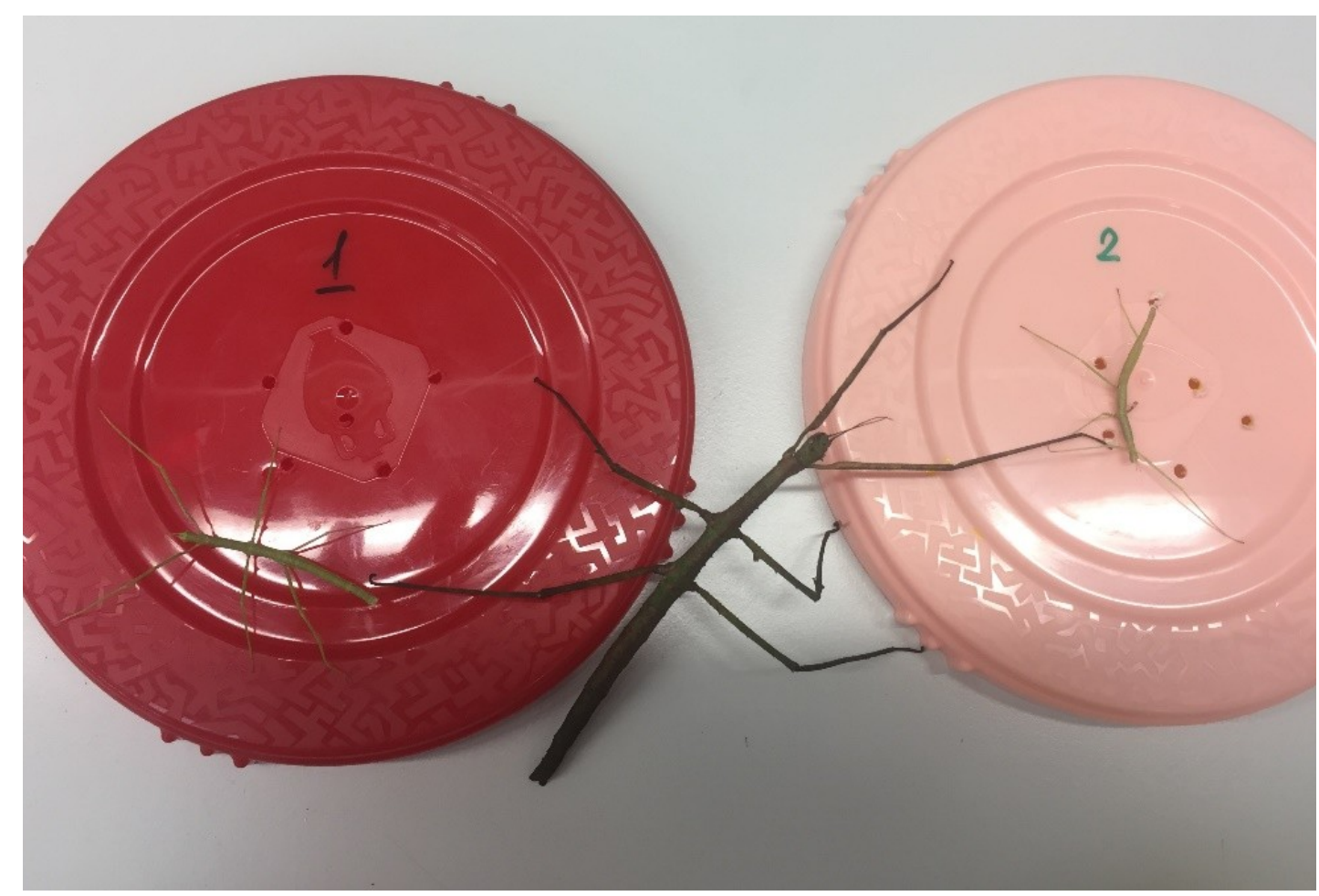

Рис 4. Сопоставление размеров и окраски палочников одного возраста. (В центре - палочник из стеклянного инсектария).

Для проверки возникшей гипотезы, мы провели еще один эксперимент. В сентябре 2020 года были отобраны 12 одновозрастных личинок и посажены по три штуки в две стеклянных однолитровых и два пластиковых контейнера из предыдущего эксперимента. При сходных с прошлогодними условиях кормления и температуры, мы получили следующие данные. Массовая гибель личинок произошла после 10 декабря (дата подсаживания личинок - 22 сентября). До начала декабря личинки хорошо ели и росли (до 3-4 стадии), после чего резко снизили пищевую активность и стали погибать 
(последний погиб 23 декабря 2020г). При этом каких-либо значимых различий в стеклянных и пластиковых боксах мы не наблюдали. Можно сказать, что материал контейнеров не влияет на жизнедеятельность палочников.

\section{2. Анализ пищевой активности палочников}

Палочники отличаются исключительно вегетарианским способом питания. Основу питания экспериментальных групп составляли листья гибискуса. При достаточной влажности срезанные листья этого растения хорошо сохраняются в инсектарии и проводимые ранее наблюдения над материнской колонией палочников показывали, что от этого корма они не отказываются. Но в нашем эксперименте мы наблюдали если не полный отказ, то, в основном, неохотное поедание. В стеклянном инсектарии такие листья буквально исчезали за ночь, две. Мы также пробовали разнообразить рацион палочников и предлагали свежие листья традесканции, высушенные листья шиповника и малины. Тем не менее, это никак не повлияло на аппетит насекомых. Можно сказать, что листья гибискуса поедались в сравнении с остальными растениями лучше всего. Однако, в сравнении с материнским стеклянным инсектарием, во всех экспериментальных колониях (даже в пятилитровой емкости) слабая пищевая активность, скорее всего, повлияла на замедление роста и последующую гибель всех образцов на личиночных стадиях. Подобная картина наблюдалась и осенью 2020года.

\section{3. Анализ динамики окраски палочников}

При подборе опытных групп палочников учитывались примерно одинаковые возраст и размеры насекомых. Но очень важным для нас был подбор одинаковых по окраске личинок. Это было несложно. Большое количество нимф и их очень близкие характеристики окраски позволили легко набрать необходимый материал. Все личинки обладали светло-бурой окраской (рис 5). Можно предположить, что в природе они занимают свой определенный 
экотоп среди мелких веточек растений. Фиксируя линьки, мы особенно педантично

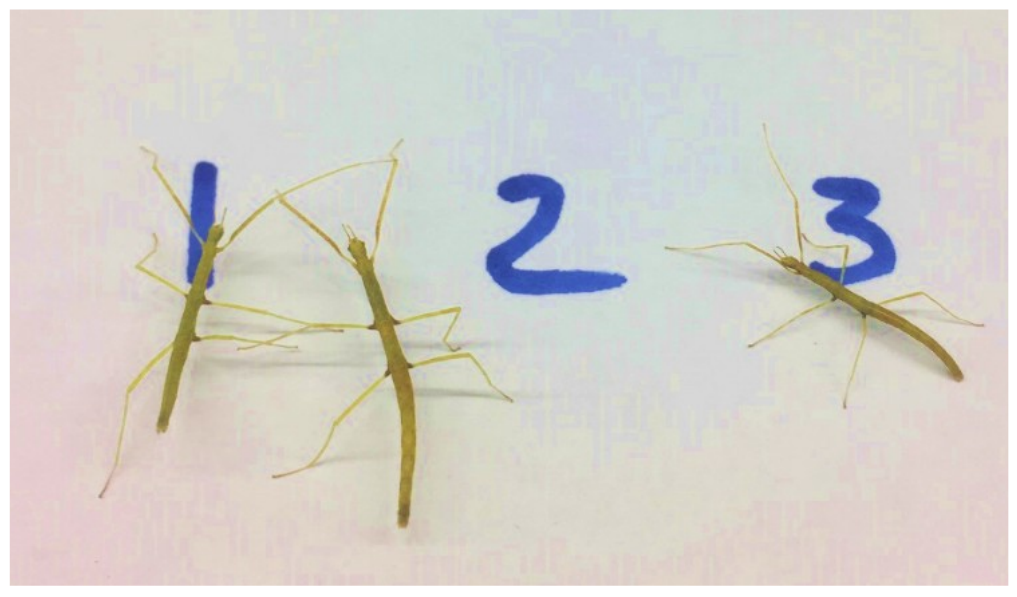

Рис 5. Преобладающая расцветка подопытных палочников.

отмечали изменения окраски. Точно можно сказать, что окраска контейнеров никак не повлияла на внешний вид личинок палочников. В разных контейнерах у личинок после линьки можно было наблюдать незначительное позеленение тела или лапок. Ни покраснения, ни пожелтения ни в одном из контейнеров не произошло. Даже в зеленом боксе никаких маскирующих оттенков соответствующего цвета не произошло. Более того, как было сказано выше, в этом контейнере выживаемость и продолжительность жизни были минимальными. Полученные нами данные по этой части исследования не могут считаться завершенными. Главная проблема, с которой мы столкнулись - малое количество линек, через которые прошли насекомые. В стеклянном инсектарии, где личинки вырастали до взрослого состояния, мы часто наблюдали ярко-зеленую окраску на предпоследней стадии. Возможно, на этой стадии может проявляться изменение окраски и в другую сторону. Все это требует дополнительных исследований. В 2020 году при проведении эксперимента с материалом контейнеров также не было получено ни одного палочника с изменившейся под внешние условия окраской.

\section{Заключение}


Проведенный нами эксперимент может считаться практически завершенным. В ходе проведенных почти двухлетних исследований нам удалось получить данные о том, что материал из которого выполнены контейнеры не влияет на продолжительность жизни палочников. Ни в одном из опытных контейнеров нимфы палочников не смогли достигнуть половой зрелости и дойти до стадии имаго. Вероятнее всего, на это повлиял объем контейнеров. Слишком малые размеры контейнеров негативно сказываются на двигательной активности палочников, и, в итоге, на пищевую. Можно предположить, что в природе личинки третьей, четвертой стадии должны мигрировать по дереву и устранять, таким образом, пищевую конкуренцию с меньшими и большими особями. Нами отмечено частое появление на четвертой - пятой стадиях развития в основном инсектарии большого числа ярко -зеленых особей. Это может свидетельствовать об их предпочтении жить в таком виде на другом ярусе дерева.

Продолжительность жизни палочников в опытных контейнерах составила от 70 до 120 суток. Стоит отметить, что в родной колонии палочников в стеклянном инсектарии изредка наблюдалась гибель отдельных особей, но к январю часть из них уже достигла половой зрелости и ряд особей выделялся на стадии предпоследней линьки яркой зелёной окраской.

Важнейшей частью эксперимента было провоцирование изменения окраски под влиянием внешне различной цветовой гаммы. В ходе эксперимента ни разу не был выявлен случай изменения покровов тела насекомых. Это может свидетельствовать о высокой наследуемости и низкой изменчивости признака окраски тела у аннамского палочника. Не стоит забывать фактор особенного - партеногенетического размножения, при котором особи обладают фактически одинаковым генотипом. Вероятнее всего, для получения отличных по цвету покрова палочников необходимо использовать метод искусственного мутагенеза. 


\section{Список использованных источников}

1. Задвинский,, В. Medauroidea extradentata: Аннамский палочник [Электронный ресурс]/ Режим доступа: Задвинский В.

http://binomen.ru/index.php/chlenistonogie/17-medauroidea-extradentata-annamskijpalochnik

2. Крапивный, А.П., Радкевич, В.А., Тихонова, Н.И., Краткий зоологический словарь [Текст] / Крапивный А.П., Радкевич В.А., Тихонова Н.И. Минск.: Высшая школа,1982 - 222 с.

3. Чудинович, К. Определение оптимальных условий содержания палочника аннамского в домашнем инсектарии [Электронный ресурс]/ Режим доступа: Чудинович K. https://school-science.ru/5/1/34626

4. Скворцова,О. Изучение жизненного цикла аннамского палочника [Электронный peсурс]/ Режим доступа: Скворцова O. https://infourok.ru/issledovatelskaya-rabotaizuchenie-zhiznennogo-cikla-annamskogo-palochnika-3342305.html

5. Шмелева, В. Изучение поведения филиппинского палочника в лабораторных условиях [Электронный ресурс]/ Режим доступа:

https://nsportal.ru/ap/library/drugoe/2017/01/29/izuchenie-povedeniya-filippinskogopalochnika-v-laboratornyh-usloviyah

6. Дымшиц, Г.М., Беляев, Д.К., Кузнецова, Л.Н. Биология. 10 класс. Учебник. Базовый уровень. ФГОС [Текст] / Дымшиц Г.М., Беляев Д.К., Кузнецова Л.Н. М.:Просвещение, 2019 - 223с.

7. Морфология насекомых. Окраска тела [Электронный ресурс]/ Режим доступа: http://www.entomologa.ru/book/13.htm

8. Строение насекомых. Окраска насекомых Электронный ресурс]/ Режим доступа: http://www.pesticidy.ru/dictionary/insect_coloring 
Приложение 1

Эксперимент по оценке влияния материала контейнера на жизнедеятельность палочников

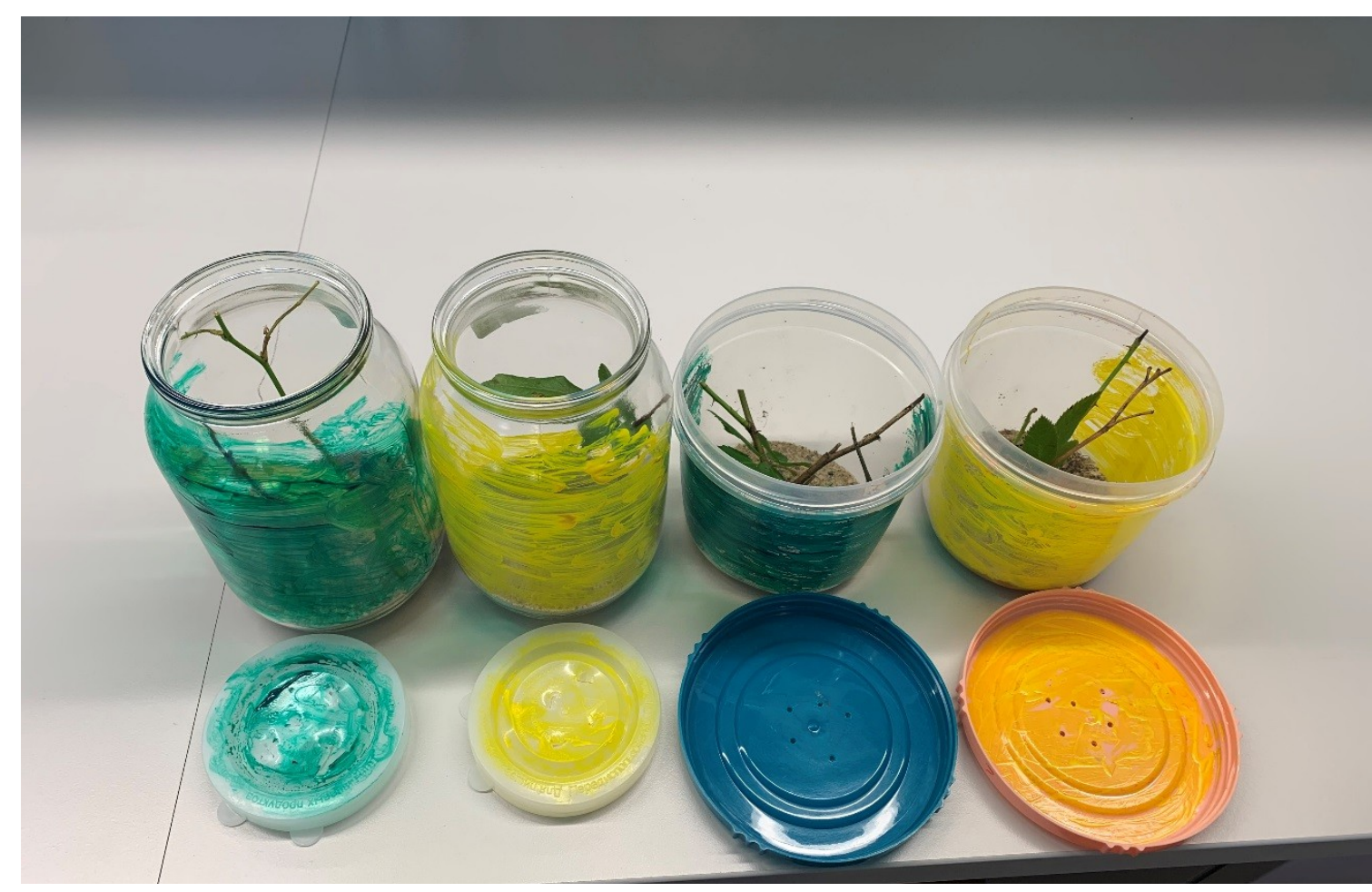

